\title{
Vitamin D status in school children in Northern Ireland
}

\author{
D.U. Glatt ${ }^{1,2}$, M.M. Slevin ${ }^{1}$, L. Beggan ${ }^{1,3}$, L.K. Pourshahidi ${ }^{1}$, E. McSorley ${ }^{1}$, \\ R. Revuelta Iniesta ${ }^{4}$, J. McCluskey ${ }^{2}$, N. Gleeson ${ }^{2}$, D.F. Cobice ${ }^{3}$, S. Dobbin ${ }^{3}$ and P.J. Magee ${ }^{1}$ \\ ${ }^{1}$ Nutrition Innovation Centre for Food and Health (NICHE), Ulster University, Coleraine, UK, \\ ${ }^{2}$ Department of Dietetics and Nutrition, Queen Margaret University, Edinburgh, UK, \\ ${ }^{3}$ Mass Spectrometry Centre, Biomedical Sciences Research Institute (BMSRI), Ulster University, Coleraine, UK and \\ ${ }^{4}$ Department of Sports and Health Sciences, University of Exeter, Exeter, UK
}

Vitamin D status in the UK is currently clinically defined by circulating 25-hydroxyvitamin D (25(OH)D) concentrations (deficient: $<25 \mathrm{nmol} / \mathrm{L}$, insufficient: $25-50 \mathrm{nmol} / \mathrm{L}$, sufficient: $>50 \mathrm{nmol} / \mathrm{L}$ ) which are set to prevent rickets and osteocalcin ${ }^{(1)}$. Risk factors for vitamin D deficiency can include season, latitude, skin pigmentation, skin cover habits, socioeconomic factors, and body composition $^{(2)}$. The most recent NDNS evidence (for England, Scotland, and Wales only) estimates that $19 \%$ of children (4 to 10 years) are vitamin $\mathrm{D}$ deficient by the end of the winter months, with circulating $25(\mathrm{OH}) \mathrm{D}$ at its lowest in January-March ${ }^{(3)}$. Currently there is no research investigating $25(\mathrm{OH}) \mathrm{D}$ concentrations in school children in Northern Ireland.

The primary aim of the D-VinCHI study was to investigate the vitamin D status of healthy school children (aged 4-11 years) in Northern Ireland. Healthy children were recruited between November 2019 and March 2020. Anthropometry was assessed (height, weight, body mass index (BMI), along with upper-arm muscle and fat area). Plasma 25(OH)D (nmol/L) (LCMS/MS) and parathyroid hormone (immunoassay) were determined. Dietary vitamin D intake was estimated using a food frequency questionnaire (FFQ) ${ }^{(4)}$. Participant's habits and behaviour was established via parent-completed questionnaires. Statistical differences were investigated using Mann-Whitney, Kruskal-Wallis or Chi-square tests as appropriate.

A total of 47 white Caucasian children (29 girls; 18 boys) were recruited from 31 families with a mean (SD) age of 8.1(2.1) years. Mean(SD) 25(OH)D was 49.17(17.04) nmol/L; 44.7\% of the children were sufficient, $48.9 \%$ insufficient and $6.4 \%$ deficient. Mean(SD) dietary vitamin $\mathrm{D}$ intake was $6.4(5.6) \mu \mathrm{g}$ /day $(\mathrm{n}=44)$. Median vitamin $\mathrm{D}$ intake was significantly higher in children classified as insufficient when compared to children classified as deficient $(4.6 \mathrm{vs} 0.9 \mu \mathrm{g} / \mathrm{day} ; \mathrm{p}=0.008)$ and the median number of vitamin $\mathrm{D}$ containing food groups consumed was significantly lower in deficient when compared to sufficient children $(5 \mathrm{vs}$. 8 groups, $\mathrm{p}=0.032)$. Dietary vitamin D intake was significantly higher in supplement users $(17 \%, n=8$; median: $15.4 \mu \mathrm{g} / \mathrm{day})$ vs. non-supplement users $(83 \%, \mathrm{n}=39$; median: $3.8 \mu \mathrm{g} / \mathrm{day})(\mathrm{p}<0.001)$. Among supplement users, seven $(88 \%)$ children were sufficient and one child $(12 \%)$ was insufficient. Vitamin D status was significantly associated with taking supplements $(\mathrm{p}=0.028)($ children with a sufficient status were found to have higher supplement intakes) and with median weekly spring/summer hours spent outside $(p=0.048)(\mathrm{children}$ with a sufficient status had more hours outside).

This study demonstrates that $55 \%(n=26)$ of the children had a deficient or insufficient vitamin $\mathrm{D}$ status throughout the winter. Encouraging supplementation, the consumption of vitamin D rich foods, and the promotion of outdoor activities is important for optimal vitamin D status in children during the winter. This preliminary evidence supports the need for further research, including larger intervention studies, to inform future public health policy for the prevention of vitamin D deficiency in children.

\section{References}

1. NICE cks (2020) [Available at: cks.nice.org.uk/topics/vitamin-d-deficiency-in-children/]

2. Scientific Advisory Committee on Nutrition (SACN) Vitamin D and Health Reort (2016) [Available at: gov.uk/government/publications/ sacn-vitamin-d-and-health-report]

3. Public Health England (2019) National Diet and Nutrition Survey (2019) [Available at: gov.uk/government/statistics/ndns-results-from-years9-to-11-2016-to-2017-and-2018-to-2019]

4. Weir RR, Carson EL, Mulhern MS, et al. (2016) J Hum Nutr Diet 255-61. 